\title{
Correction to: Finite element analysis of two cephalomedullary nails in treatment of elderly reverse obliquity intertrochanteric fractures: zimmer natural nail and proximal femoral nail antirotation-II
}

Jian Chen ${ }^{1+}$, Jian-xiong Ma ${ }^{2+}$, Ying Wang ${ }^{2}$, Hao-hao Bai ${ }^{2}$, Lei Sun ${ }^{2}$, Yan Wang ${ }^{2}$, Bin Lu², Ben-chao Dong ${ }^{2}$, Ai-xian $\operatorname{Tian}^{2}$ and Xin-long Ma ${ }^{1 *}$

\section{Correction to: J Orthop Surg Res} https://doi.org/10.1186/s13018-019-1468-3

In the original publication of this article [1], Chinese text of the Figs. 3, 4, 5 has not been converted to English.

Corrected figures are shown below.

\author{
Author details \\ 'Department of Orthopedics, Tianjin Medical University General Hospital, \\ Tianjin 300052, People's Republic of China. ${ }^{2}$ Institute of Orthopedics, Tianjin \\ Hospital, Tianjin University, Tianjin 300050, People's Republic of China.
}

Published online: 09 March 2020

\section{Reference}

1. Chen, et al. J Orthop Surg Res. 2019;14:422.

The original article can be found online at https://doi.org/10.1186/s13018 019-1468-3

*Correspondence: maxinlongtj@163.coms

${ }^{\dagger} J$ ian Chen and Jian-xiong Ma contributed equally to this work.

'Department of Orthopedics, Tianjin Medical University General Hospital, Tianjin 300052, People's Republic of China

Full list of author information is available at the end of the article

C C The Author(s). 2020 Open Access This article is licensed under a Creative Commons Attribution 4.0 International License, which permits use, sharing, adaptation, distribution and reproduction in any medium or format, as long as you give appropriate credit to the original author(s) and the source, provide a link to the Creative Commons licence, and indicate if changes were made. The images or other third party material in this article are included in the article's Creative Commons licence, unless indicated otherwise in a credit line to the material. If material is not included in the article's Creative Commons licence and your intended use is not permitted by statutory regulation or exceeds the permitted use, you will need to obtain permission directly from the copyright holder. To view a copy of this licence, visit http://creativecommons.org/licenses/by/4.0/. The Creative Commons Public Domain Dedication waiver (http://creativecommons.org/publicdomain/zero/1.0/) applies to the data made available in this article, unless otherwise stated in a credit line to the data. 


\section{a}

S, Mises
(Avg:75\%)

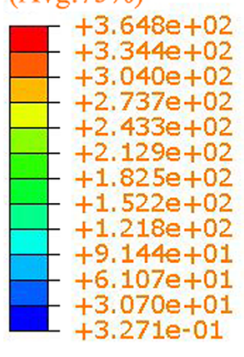

Max: $+3.648 \mathrm{e}+02$

Elem: ZNN.44832

Node: 20948

Min: +3.274e-01

Elem: ZNN.39701

Node: 324

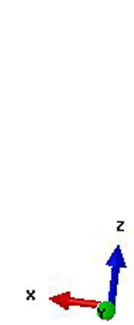

b

\section{$\mathrm{S}$, Mises}

(Avg:75\%)

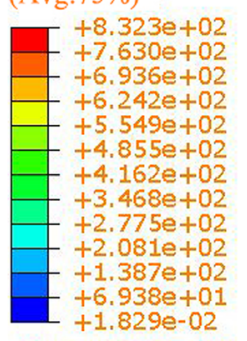

Max: $+8.323 \mathrm{e}+02$

Elem: PFNA. 103358

Node: 25921

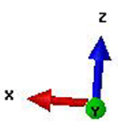

Fig. 3 Stress distribution, peak and position analysis for internal fixation (a ZNN model, b PFNA-II model) a
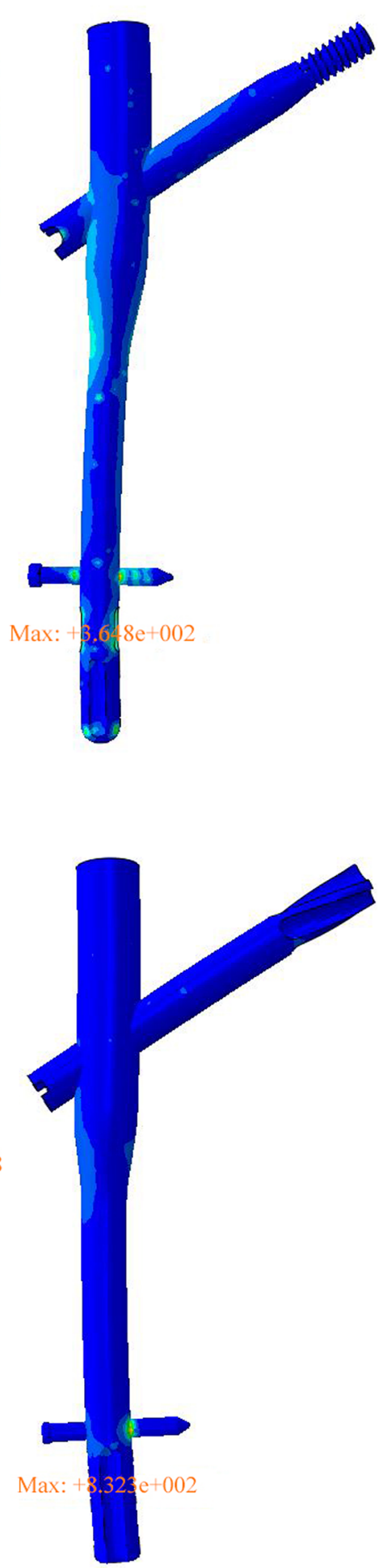

b

S, Mises (Avg:75\%)

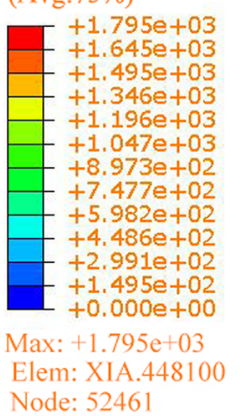

Node: 52461

(Avg:75\%)

$+1.718 e+02$

$+1.575 \mathrm{e}+02$

$+1.432 \mathrm{e}+02$

$+1.289 \mathrm{e}+02$

$+1.146 e+02$

$+8.593 e+01$

$+7.162 \mathrm{e}+01$

$+5.730 \mathrm{e}+01$

$+4.298 \mathrm{e}+01$

$+2.866 e+01$

$+1.435 e+01$

Max: $+1.718 \mathrm{e}+02$

Elem: XIA.167554

Node: 80001
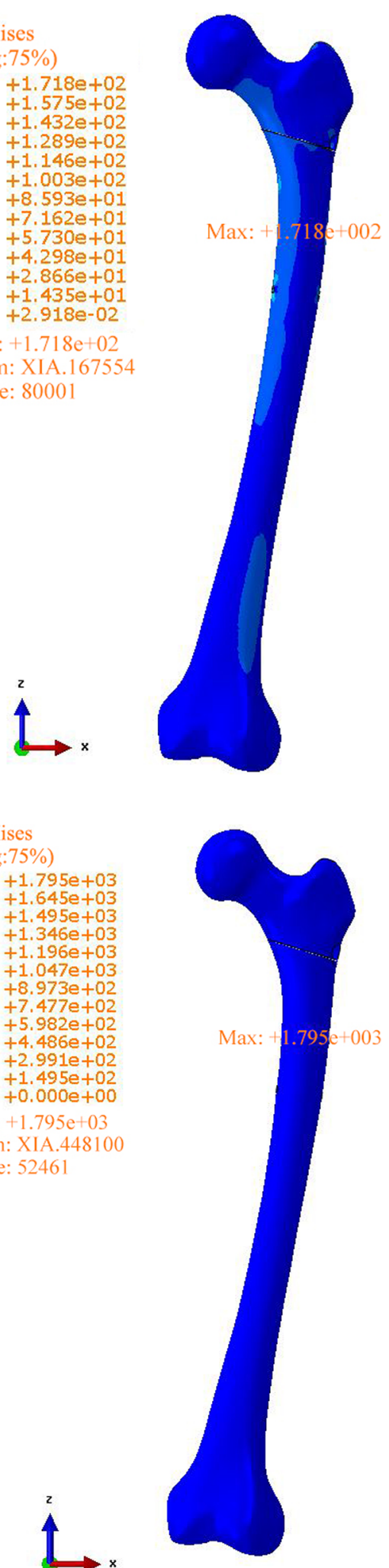

Fig. 4 Stress distribution, peak and position analysis for femur (a ZNN model, b PFNA-II model) 


\section{a}

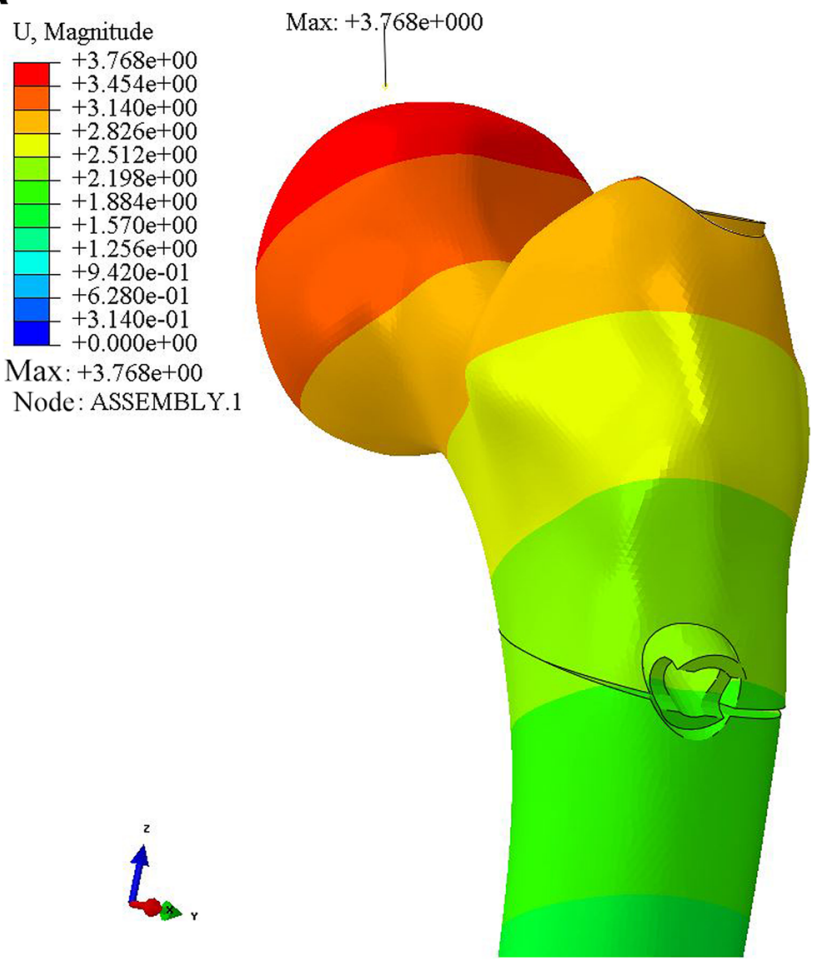

b

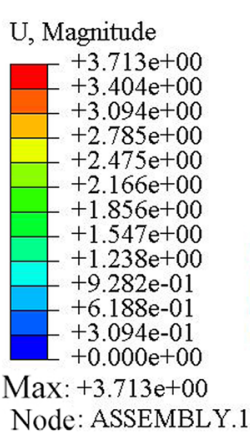

Max: $+3.713 \mathrm{e}+000$

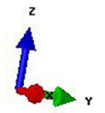

$130+000$
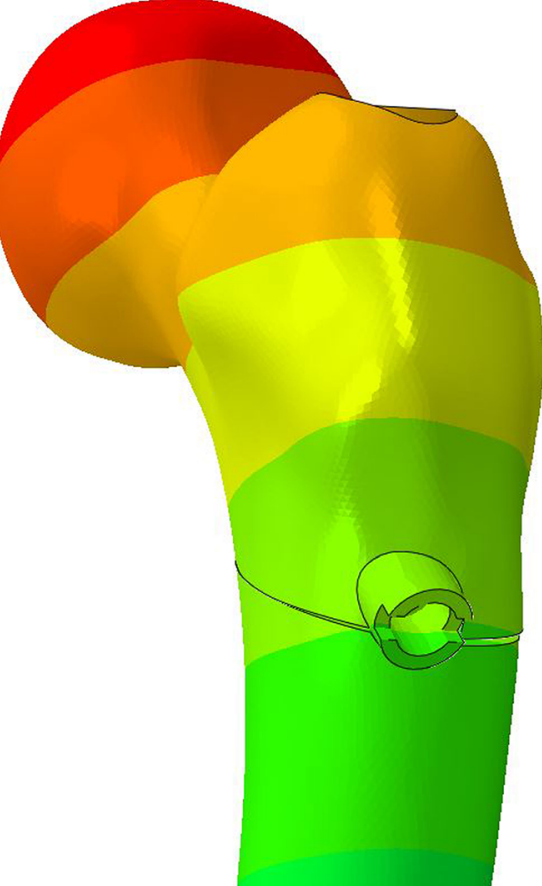

Fig. 5 Displacement distribution, maximum amount and position of two models (a ZNN model, b PFNA-II model) 